\title{
NON-SYNDROMIC OLIGODONTIA IN PERMANENT DENTITION: A CASE REPORT
}

\author{
P. PANNU ${ }^{1}$, V. GALHOTRA ${ }^{1}$, P. AHLUWALAI ${ }^{1}$, R. S. GAMBHIR ${ }^{2}$ \\ ${ }^{1}$ Gian Sagar Dental College and Hospital - Pediatric and Preventive Dentistry, Rajpura, India \\ ${ }^{2}$ Sector 7C, Chandigarh, Chandigarh 160019, India
}

DOI: http://dx.doi.org/10.4314/gmj.v48i3.11

Corresponding Author: Dr. R.S. Gambhir

Email:raman1g@yahoo.co.in

Conflict of Interest: None declared

\section{SUMMARY}

Tooth agenesis is one of the most common congenital anomalies seen in humans. Although absence of one or more teeth is common but absence of multiple teeth is rare. Oligodontia is a rare developmental anomaly, involving agenesis of six or more permanent teeth, excluding the third molars. The reported prevalence of oligodontia in permanent dentition is $0.14 \%$. Oligodontia can present as an isolated condition or as a part of a syndrome. The present case report highlights a unique case of non syndromic oligodontia, with agenesis of four permanent incisors, left permanent canine and right second premolar in the mandibular arch and its management with a novel fixed functional prosthetic appliance. Prosthetic rehabilitation is an urgent need for these kind of patients so that they do not suffer from masticatory and esthetic problems which can eventually lower the self esteem of individuals.

Key words: Mandible, Permanent dentition, Nonsyndromic, Agenesis, Oligodontia

\section{INTRODUCTION}

Tooth agenesis is the most prevalent craniofacial congenital malformation in humans. ${ }^{1}$ Various terms used to explain absence of teeth is hypodontia, oligodontia and anodoontia. Oligodontia is relatively a rare condition, probably affecting about 0.1 to $1.2 \%$ of the population. ${ }^{2}$ The most commonly missing permanent teeth are the third molars $(9-37 \%)$, followed by mandibular second premolars $(<3 \%)$, maxillary lateral incisors $(<2 \%)$ and maxillary second premolars and mandibular incisors $(<1 \%){ }^{3}$

The exact etiology of agenesis of teeth is not clear but genetic factors are thought to play a definite role. Anomalies in the development of the mandibular symphysis, shortened arches as an evolutionary trend and endocrinal disturbances may affect dental tissues responsible for forming tooth buds thus resulting in congenital absence of lower incisors. ${ }^{4}$ The reported envi- ronmental factors associated with agenesis of teeth are localized infection of the jaw (which might destroy the tooth buds), any disturbance of the endocrinal system, systemic infection (rubella), trauma in apical region of dentoalveolar process (due to fractures or while doing extraction of deciduous teeth), chemical substances or drugs (use of thalidomide or chemotherapy), radiation therapy or disturbances in jaw innervations. ${ }^{5}$

Oligodontia may occur as a feature of a specific disease such as anhidrotic ectodermal dysplasia, incontinentia pigmenti (an X-linked genetic disorder that affects the ectodermal structures and is associated with congenital tooth absence and abnormal form), Down's syndrome, Pierre Robin syndrome, and Ehler Danlos syndrome. ${ }^{6}$ It can also present as an isolated condition (non syndromic) and has been linked to mutations of MSX1, PAX9 and EDA genes. ${ }^{7}$

There is a wide arena of treatment options available ranging from removable/fixed prosthesis to dental implants at a later age. Dental implants can be placed, restored and loaded in children suffering from syndromes like oligodontia and ectodermal dysplasia., An 8-year old boy suffering from this congenital syndrome was successfully given implants and functionally loaded which resulted in high patient satisfaction. ${ }^{8}$ According to an another recent report, an11-year old patient with a history of oligodontia and hypohidrotic ectodermal dysplasia was treated successfully using implants placed in the anterior and posterior mandible as part of his prosthetic rehabilitation. ${ }^{10}$ This paper presents a case of non syndromic oligodontia, with agenesis of four permanent incisors, left permanent canine and right second premolar in the mandibular arch and its management. 


\section{CASE REPORT}

An 8-year- old girl reported to the Department of Pediatric Dentistry with the chief complaint of missing lower front teeth. The parents had observed this condition since early childhood but did not seek any dental consultation and there was no history of any previous trauma or extraction. Past medical and family histories were noncontributory. The frontal view of the patient depicts a well-balanced face, and a convex facial profile was observed in lateral view [Figure 1 (a) and (b)].

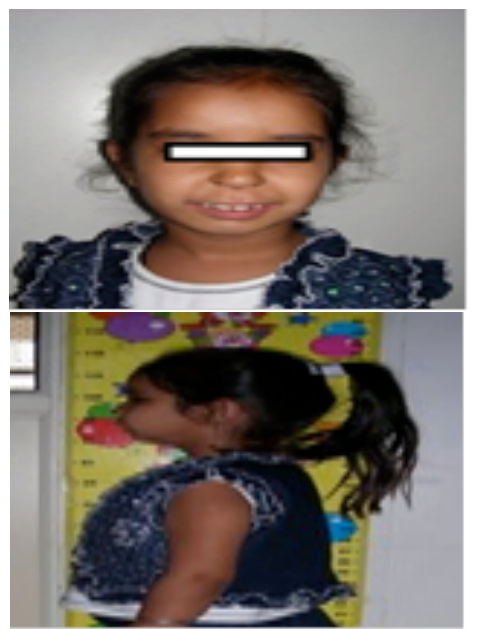

Figures 1a and 1b Frontal view (a) and Lateral view (b) of the patient

Intraoral examination revealed mixed dentition stage, with mesial step molar relationship, root stumps of 52 , $61,62,73,84$, missing $41,45,31,33$ and multiple carious teeth (Figure 2).

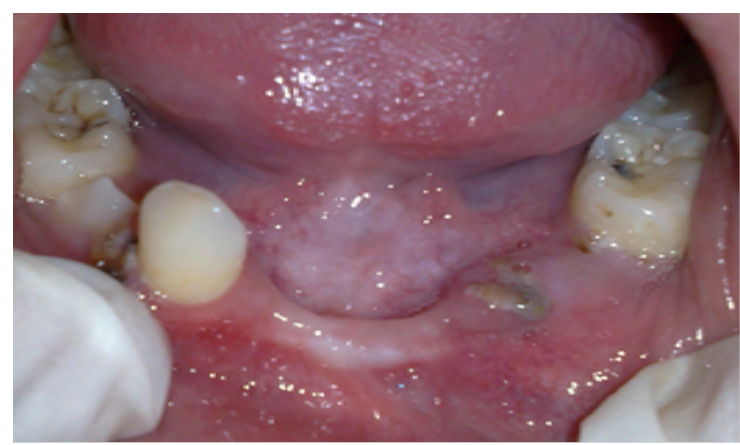

Figure 2 Pre-operative photograph of mandibular arch

The alveolar ridge in the mandibular anterior region was typically knifed edged, suggesting absence of mandibular anterior teeth. To ascertain the provisional diagnosis, an orthopantanograph was advised which revealed no evidence of development of $31,32,33,41$, 42, 45 (Figure 3). Parents were informed about the agenesis of six mandibular permanent teeth.
To rule out any syndromic involvement, the patient was referred to Department of Pediatrics and the medical evaluation of the child, revealed absence of any syndrome. Abnormalities of PAX2, PAX3, PAX6, and PAX9 are associated with various congenital craniofacial anomalies, including tooth abnormalities. ${ }^{11,12}$

Karyotyping and Cyto SNP assay were done to detect any chromosomal aberrations responsible for agenesis of the teeth; however no significant findings could be ascertained.

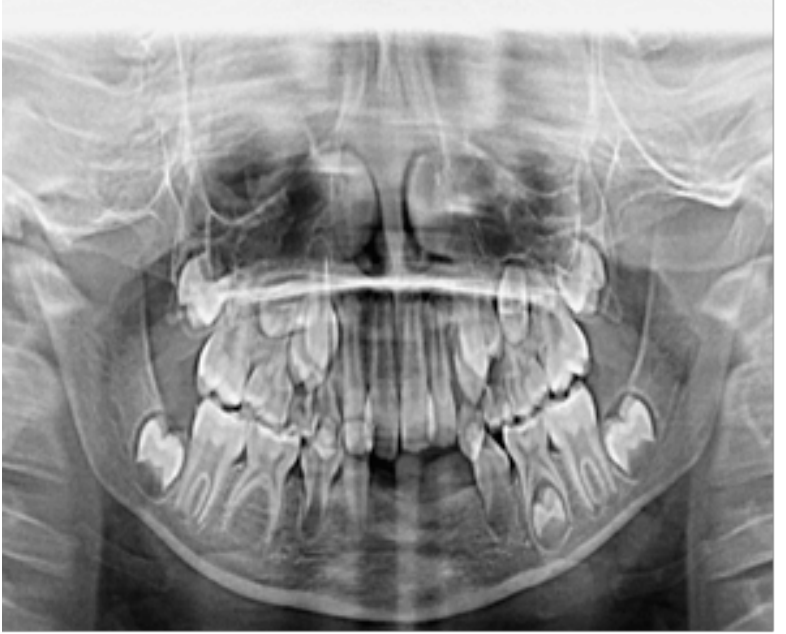

Figure 3 Orthopantamograph of the patient revealing no evidence of development of 31, 32, 33, 41, 42, 45

Karyotyping was done to evaluate any structural changes in chromosomes and count the number of chromosomes so as to ascertain genetic problem. None of the family members suffered from a similar condition, suggesting absence of hereditary basis to the present defect.

The treatment plan comprised of thorough oral prophylaxis, placement of pit and fissure sealants, restoration of carious teeth, extraction of root stumps of deciduous teeth, followed by fixed prosthetic replacement of the congenitally missing mandibular teeth was done using acrylic teeth attached to a lingual arch (Figure 4).

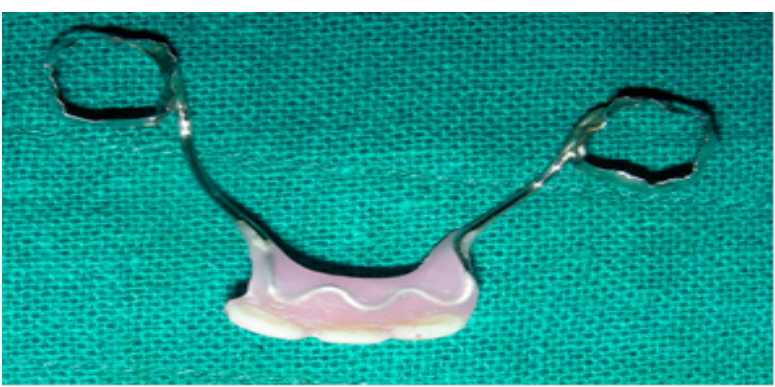

Figure 4 Photograph of appliance before insertion 


\section{DISCUSSION}

A tooth may be considered to be congenitally missing if it cannot be discerned clinically or radio graphically and no history exists of its extraction. ${ }^{13}$ The child in our case report was eight years old and no evidence of calcification of the six permanent teeth could be seen, thereby ascertaining the agenesis of the aforementioned teeth.

Different theories have been put forward to explain the etiology of agenesis of teeth. Kjaer and coworkers ${ }^{14}$ proposed a theory stating that tooth agenesis may result from an abnormality in peripheral nerve supply, in the overlying epithelium (as seen in ectodermal dysplasia) or in supporting bone. They demonstrated that teeth located near peripheral nerve endings are the most affected by agenesis and hypodontia could be associated with missing mandibular canal. However, in this case report, the overlying mucosa was found to be normal and radiographic examination of mandible showed the presence of both mental foramen and mandibular canal, suggesting a normal neural innervation.

In this case report, oligodontia could not be associated with any syndrome as the thorough assessment by the pediatrician, Karyotyping and Cyto SNP assay did not reveal any significant findings. None of the family members suffered from a similar condition, suggesting absence of hereditary basis to the present defect. The prenatal and post natal histories were noncontributory to suggest any environmental cause. Agenesis of mandibular incisors has been reported but unilateral absence of a second premolar and contralateral canine is rare. $^{4,15}$

The treatment options available using dental prosthesis vary from removable/ fixed prosthesis to dental implants at a later age as dental implants can be given once the period of active growth is over. Long-term rehabilitation plan of the patient with dental implants was discussed with the parents but because of financial constraints, parents resorted to economical treatment modality. May be at a later stage, implants can be considered as a permanent treatment. So the choice of treatment in the present case was that of a removable or a fixed prosthesis but as the child was school going and did not want a removable prosthesis, hence the decision for fabrication of a fixed prosthesis was made.

The design of the appliance comprised of a wire mesh over the ridge area (clearance of $1.5 \mathrm{~mm}$ ) of missing teeth, soldered to the bands on permanent molars. Keeping in mind the space required for erupting premolar on left side, three incisors were placed in heat cure acrylic over the mesh. A periodic recall was ad- vised every three months when the appliance would be removed and fluoride application would be done on banded molars to prevent their decalcification. The parents were informed that prosthesis would need to be replaced as per growth changes from time to time and at a later age dental implants would be a better treatment option for complete rehabilitation.

\section{CONCLUSION}

A patient presenting with missing teeth suffers not only from masticatory and esthetic problems but psychological stress as well, as it can lower the self-esteem of an otherwise healthy individual. Dental rehabilitation of such patients requires orthodontic and prosthetic intervention at the appropriate time jointly by a pediatric dentist and other dental specialists to improve oral health and psyche of the child.

\section{REFERENCES}

1. Matalova E, Fleischmannova J, Sharpe PT, Tucker AS. Tooth agenesis: from molecular genetics to molecular dentistry. J Dent Res 2008:87:617-23.

2. Worsaae N, Jensen BN, Holm B, Holsko J. Treatment of severe hypodontia-oligodontia--an interdisciplinary concept. Int J Oral Maxillofac Surg 2007;36(6):473-80.

3. Grahen HJ. Hypodontia in permanent dentition. Odontol Rev 1956;7:1.

4. De Coster PJ, Marks LA, Martens LC, Huysseune. Dental agenesis: genetic and clinical perspectives. J Oral Pathol Med 2009; 38:1-17.

5. Mattheeuws N, Dermaut L, Martens G. Has hypoontia increased in Caucasians during the $20^{\text {th }}$ century? A meta-analysis. Eur J Orthod 2004; 26:99-103.

6. Suda N, Ogawa T, Kojima T, Saito C, Moriyama $\mathrm{K}$. Non syndromic oligodontia with a novel mutation of Pax 9. J Dent Res 2011;90(3):382-6.

7. Kurisu K, Tabata MJ. Review. Human genes for dental anomalies. Oral Diseases 1997;3:223-8.

8. Kramer FJ, Baethge C, Tschernitschek H. Implants in children with ectodermal dysplasia: a case report and literature review. Clin Oral Implants Res 2007;18(1):140-6.

9. Sweeney IP, Ferguson JW, Heggie AA, Lucas JO. Treatment outcomes for adolescent ectodermal dysplasia patients treated with dental implants. Int J Paediatr Dent 2005; 15(4):241-8.

10. Singer SL, Henry PJ, Liddelow G, Rosenberg I. Long-term follow-up of implant treatment for oligodontia in an actively growing individual: a clinical report. J Prosthet Dent 2012; 108(5):279-85.

11. Haldeman-Englert CR, Biser A, Zackai EH, Ming JE. Revision of "A 223-kb de novo deletion of 
PAX9 in a patient with oligodontia". J Craniofac Surg 2012;23(2):149-51.

12. Swinnen S, Bailleul-Forestier I, Arte S, Nieminen $\mathrm{P}$, Devriendt K, Carels C. Investigating the etiology of multiple tooth agenesis in three sisters with severe oligodontia. Orthod Craniofac Res 2008; 11(1):24-31.

13. Schalk-Van Der Weide Y, Bosman F. Tooth size in relatives of individuals with oligodontia. Arch Oral Biol 1996; 41:469-72.
14. Kjaer I, Kcosis G, Nodal M, Christensen LR. Aetiological aspects of mandibular tooth agenesisfocusing on the role of nerve, oral mucosa, and supporting tissues. Eur J Orthod 1994; 16(5):3715.

15. Endo T, Ozoe R, Kojima K, Shimooka S. Congenitally missing mandibular incisors and mandibular symphysis morphology. Angle Orthod 2007; 77:1079-84. 